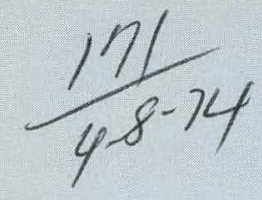

\title{
INFLUENCE OF PRESSURE VARIATIONS ON THE FOCUS OF ELECTRON BEAMS USED FOR WELDING
}

G. W. Brandon, Jr

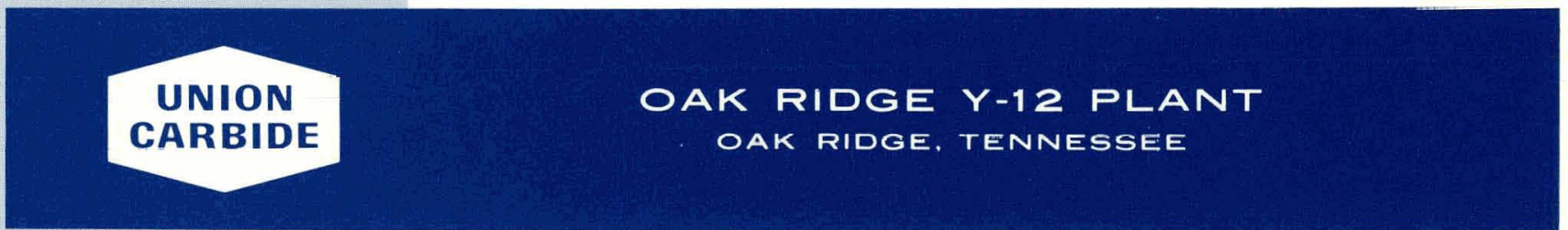

prepared for the U.S. ATOMIC ENERGY COMMISSION

under U.S. GOVERNMENT Contract W.7405 eng 26 


\section{DISCLAIMER}

This report was prepared as an account of work sponsored by an agency of the United States Government. Neither the United States Government nor any agency Thereof, nor any of their employees, makes any warranty, express or implied, or assumes any legal liability or responsibility for the accuracy, completeness, or usefulness of any information, apparatus, product, or process disclosed, or represents that its use would not infringe privately owned rights. Reference herein to any specific commercial product, process, or service by trade name, trademark, manufacturer, or otherwise does not necessarily constitute or imply its endorsement, recommendation, or favoring by the United States Government or any agency thereof. The views and opinions of authors expressed herein do not necessarily state or reflect those of the United States Government or any agency thereof. 


\section{DISCLAIMER}

Portions of this document may be illegible in electronic image products. Images are produced from the best available original document. 
Reference to a company or product name does not imply approval or recommendation of the product by Union Carbide Corporation or the U.S. Atomic Energy Commission to the exclusion of others that may meet specifications.

Printed in the United States of America. Avallable trom National Technical Information Service

U.S. Department of Commerce

5285 Port Royal Road, Springfield, Virginia 22151

Price: Printed Copy \$4.00; Microfiche $\$ 1.45$

This report was prepared as an account of work sponsored by the United States Government. Neither the United States nor the United States Atomic Energy Commission, nor any of their employees, nor any of their contractors, subcontractors, or their employees, makes any warranty, express or implied, or assumes any legal liability or responsibility for the accuracy, completeness or usefulness of any information, apparatus, product or process disclosed, or represents that its use would not infringe privately owned rights. 


\section{INFLUENCE OF PRESSURE VARIATIONS ON THE FOCUS OF ELECTRON BEAMS USED FOR WELDING}

G. W. Brandon, Jr

Oak Ridge Y-12 Plant

P.O. Box Y, Oak Ridge, Tennessee 37830

Date Issued - April 11, 1974

This report was prepared as an account of work
sponsored by the United States Government. Neither
the United States nor the United States Atomic Energy
Comnission, nor any of their employees, nor any of
their contractors, subcontractors, or their employees,
makes any warranty, express or implied, or assumes any
legal liability or responsibility for the accuracy, com-
pleteness or usefulness of any information, apparatus,
product or process disclosed, or represents that its use
would not infringe privately owned rights.

Prepared for the U.S. Atomic Energy Commission Under U.S. Government Contract W-7405eng-26 


\section{ABSTRACT}

An experimental study has shown that the variations in pressure typically experienced in an electron-beam welding chamber can significantly affect the focus of the electron beam, resulting in detectable variations in weld penetration and width. 


\section{CONTENTS}

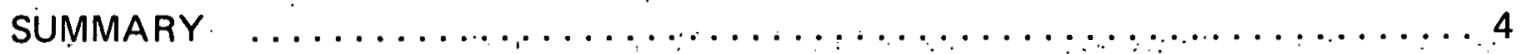

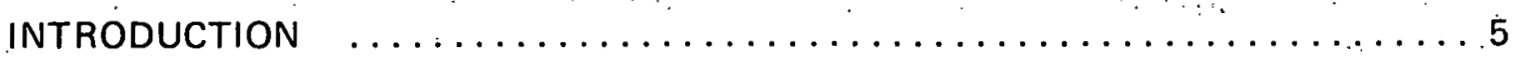

INFLUENCE OF PRESSURE VARIATIONS ON THE FOCUS OF ELECTRON BEAMS $\ldots \ldots \ldots \ldots \ldots \ldots \ldots \ldots \ldots$

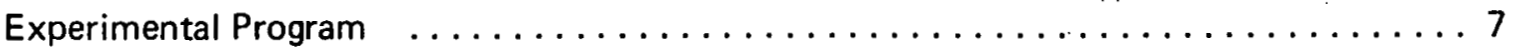

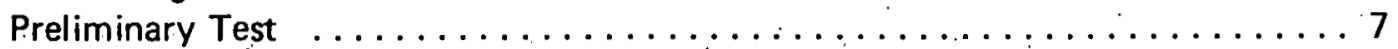

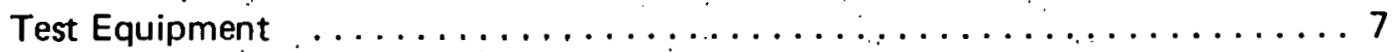

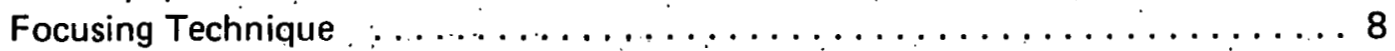

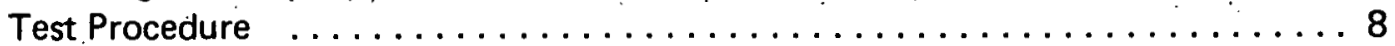

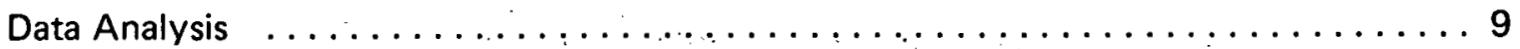

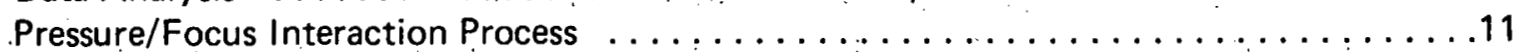

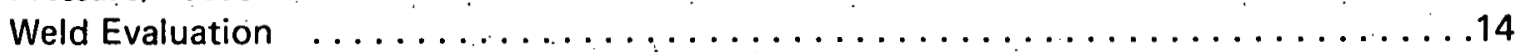

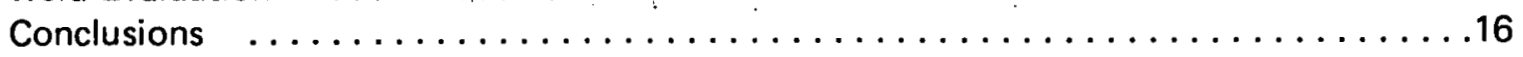

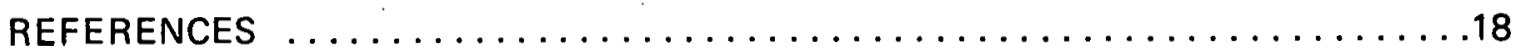




\section{SUMMARY}

An experimental study was conducted to evaluate the variations in the focus of electron beams used for welding that result from changes in chamber pressure. A series of tests were performed to demonstrate the existence and characteristics of the pressure/focus interaction. A final series of tests were completed to assess the effect of the pressure-induced focus variations on weld penetration and width.

Test results indicated that:

1. The current through the focus coil required to maintain the electron beam sharp focus at a fixed position in the welding chamber can vary approximately $20 \%$ due to pressure changes typically encountered during vacuum electron beam welding.

2. Changes in chamber pressure experienced during vacuum electron beam welding can, by disturbing the focus of the electron beam, cause weld penetration to vary. in excess of $18 \%$ for partial-penetration welds in Type 6061 aluminum alloy. 


\section{INTRODUCTION}

Electron-beam (EB) welding, since its introduction into the United States in 1958, has developed into one of the more versatile and more sophisticated joining processes now available to the industrial community. Application of EB welding techniques offers unique advantages not usually attainable with other types of welding processes. Perhaps the most important advantage is the ability to focus the electron beam to a small $(0.02 \mathrm{~cm})$ diameter, providing a high energy density and the ability to produce a relatively high depth-to-width ratio in the weld fusion zone. Whereas the more conventional welding processes typically offer depth-to-width ratios of less than 1:1, ratios in excess of 30:1 are not unusual in $E B$ welds. This ability to produce a deep, narrow fusion zone reduces the size of the adjacent heat-affected region and limits the amount of distortion produced by the welding process. In addition, EB welding conducted in a hard vacuum offers the advantage of minimizing the amount of contaminant gases in the vicinity of the weld.

Although EB welding offers unique advantages and capabilities to the welding industry, it is not without inherent anomalies and problems. One problem demanding consideration is concerned with the requirement for welding parameter stability and the effects of short-term variations in these parameters. Four basic parameters: accelerating voltage, beam current, welding speed, and focus or beam diameter, are usually considered to be the major variables requiring precision control during $E B$ welding. (1) Considerable effort has been devoted to experimental and theoretical studies that will establish the requirements for stable control of these parameters. The effects of parameter variations have been characterized in detail $(2,3)$ and are routinely considered in the preparation of procurement specifications for new instrumentation and the development of welding procedures for specific applications.

The nature of the operations $(4)$ conducted at the Oak Ridge $Y-12$ Plant $($ (a) requires that close attention be paid to weld precision and repeatability. Typical operating procedures at $Y-12$ do not, however, always require that EB welding be done at a specific chamber pressure. Normally, procedures specify only that the pressure be below a maximum level (usually $\sim 10^{-4}$ torr) when the weld is made. As a result, welding parameters, particularly focus, are not always adjusted at the same initial chamber pressure. Also, since appreciable time is necessary to complete the preparations for each weld, machine parameters may be adjusted at chamber pressures significantly different from those encountered when the actual weld is made.

Periodic reports from welding personnel have described apparent pressure-related fluctuations in the focus coil current required to obtain and repeat electron beam sharp focus for a given set of welding parameters. Observed variations in focus coil current have occasionally exceeded $\pm 15 \%$ and have resulted in considerable downtime for inspection and maintenance.

Because of the observed variations in the focus coil current and the resultant maintenance problems, an experimental study of the pressure/focus effect was initiated. This study had

(a) Operated by the Union Carbide Corporation's Nuclear Division for the US Atomic Energy Commission. 
three major objectives: (1) to verify the existence of a pressure-dependent variation in the electron beam focus, (2) to determine the magnitude and significance of this effect in relation to variations in the final weld characteristics and quality, and (3) to develop estimates of the importance of this pressure effect for any given set of welding parameters. 


\section{INFLUENCE OF PRESSURE VARIATIONS ON THE FOCUS OF ELECTRON BEAMS}

\section{EXPERIMENTAL PROGRAM}

\section{Preliminary Test}

As a result of indications that the reported variations in focus coil current required to repeat electron beam sharp focus were related to changes in welding chamber pressure, a preliminary test was conducted to establish the existence and general characteristics of a pressure/focus interaction.

This initial test was begun with the welding chamber at atmospheric pressure. Chamber evacuation was started and, as soon as the chamber pressure was reduced to $2 \times 10^{-4}$. torr, the preselected beam current and accelerating voltage $(8.4 \mathrm{ma}, 52 \mathrm{kv})$ were adjusted. Beginning at a chamber pressure of $1 \times 10^{-4}$ torr, and at successive intervals of $\sim 0.5 \times 10^{-5}$ torr, visual techniques were used to sharp focus the electron beam on a tungsten target located $40 \mathrm{~cm}$ below the heat shield. For this test, "sharp focus" was defined as the focus control setting, in digits, that provided the "smallest" beam spot size on the tungsten target, as determined optically.

Results of this initial test are reported in Figure 1. The current through the focus coil required to obtain a sharp focus at a particular value of chamber pressure is plotted as a function of the chamber pressure. As the chamber pressure decreased, the sharp focus current increased from an initial value of 235 digits at a chamber pressure of $1 \times 10^{-4}$ torr to a final value, at $5 \times 10^{-5}$ torr, of 256 digits-a total increase of 21 digits, or $9 \%$, over the pressure range investigated.

Based on the results of the preliminary test, a series of detailed experimental evaluations were planned and conducted to further characterize the pressure/focus interaction.

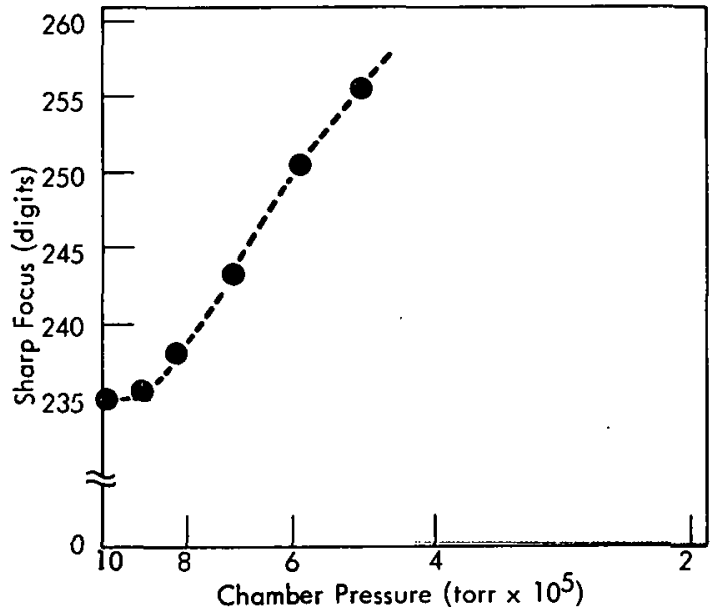

Figure 1. VARIATION IN SHARP FOCUS WITH PRESSURE.

\section{Test Equipment}

The test data included in this study were obtained using two 7.5-kilowatt Hamilton Standard electron-beam welders. The preliminary test, previously described, was completed on a standard welder, equipped with an R-4UA electron gun that is normally used for production applications. All other tests were conducted using a second R-40A gun mounted in a welder that had been previously modified for partial vacuum EB welding by the addition of a $27 \cdot \mathrm{cm}$ extension in the electron-beam column. Welding parameters were monitored using high-accuracy $( \pm 0.5 \%)$ digital meters. Welding chamber pressure control was accomplished through the installation of a precision needle valve to obtain a closely regulated vacuum leak. 


\section{Focusing Technique}

Considerable time and effort have been expended by experimenters in attempts to establish the most accurate technique for determining the point at which an electron beam has reached "sharp focus". For some electron guns, such as the Hamilton Standard S-32, visual focusing is sufficient, since the beam provides a distinct, circular spot of minimum diameter at optimum, or sharp, focus. For the other guns, such as the Hamilton Standard R-40A, visual focusing may not be adquate, due to the oval cross section of the beam and beam aberrations introduced by the beam focusing coil. In addition, there is no complete agreement, for the R-40A type of gun, concerning the actual definition of a sharp focus. Some define sharp focus as the point at which the beam spot on the target is the "brightest". Others define sharp focus as the "smallest" spot, or the point at which minimum spot width in a particular axis is obtained.

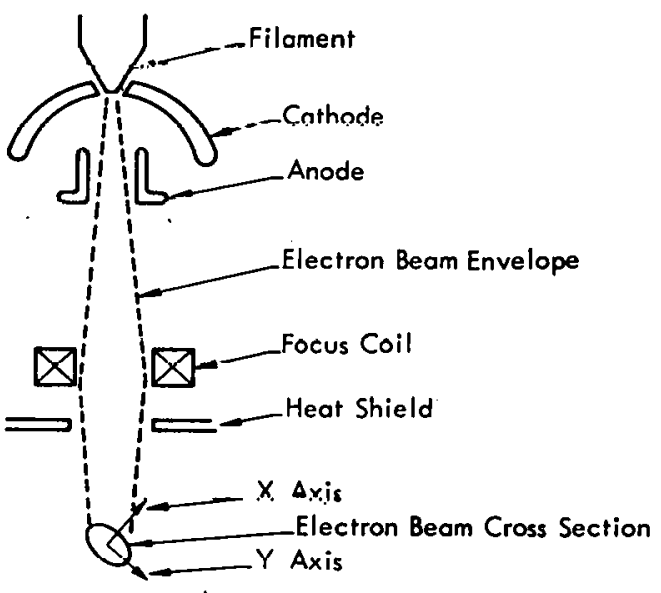

Figure 2. ELECTRON-BEAM GEOMETRY FOR THE R-40A GUN.
Although visual focusing was used to some extent during the tests included in this study, the majority of the data were obtained using an electronic "flying-wire" scanner. This scanner, basically a wire that sweeps through the electron beam, provides an output pulse with a width proportional to the diameter of the beam. By adjusting the electron beam focusing control until beam width, as measured by the scanner, is at a minimum, the subjective factor found in a visual determination of sharp focus is eliminater. For the purposes of this report, sharp focus is defined as the setting of the focus control at which minimum beam diameter in the $x$ axis is obtained, as shown in Figure 2.

Because of aberrations in the beam focusing lens, the minimum beam width in the $y$ axis for a given current through the focusing coil is not found at the same distance from the heat shield (Figure 2) as is the minimum beam width in the $x$ axis. It was determined, however, that a change in focus coil current of less than one percent was sufficient to alternate between minimum beam width in the $x$ axis and minimum beam width in the $y$ axis at the same fixed distance from the heat shield.

\section{Test Procedure}

Twenty-five tests were completed, using various combinations of beam current from 4 to 16 ma and accelerating voltages between 50 and $150 \mathrm{kv}$. The "flying-wire" scanner was used to determine the minimum beam diameter along the $x$ axis (Figure 2) at a location $23 \mathrm{~cm}$ below the heat shield.

Each test followed the same procedure. For a particular test, the preselected combination of beam current and accelerating voltage was established at a chamber pressure of $4 \times 10^{-5}$ torr. The chamber pressure was then adjusted in random sequence to each of a series of preselected values between $2 \times 10^{-4}$ and $4 \times 10^{-5}$ torr. At each value of chamber pressure, 
the focus coil current was adjusted to obtain a sharp focus, or minimum beam diameter in the $x$ axis. The focus control setting, in digits, at sharp focus was then recorded as a function of the corresponding chamber. pressure. A tabulation of the test conditions is presented in Table 1.

Table 1

SUMMARY OF TEST PARAMETERS

\begin{tabular}{rccccc}
\hline $\begin{array}{c}\text { Test } \\
\text { Number }\end{array}$ & $\begin{array}{c}\text { Accelerating } \\
\text { Voltage } \\
(\mathrm{kv})\end{array}$ & $\begin{array}{c}\text { Beam } \\
\text { Current } \\
\text { (ma) }\end{array}$ & $\begin{array}{c}\text { Test } \\
\text { Number }\end{array}$ & $\begin{array}{c}\text { Accelerating } \\
\text { Voltage } \\
\text { (kv) }\end{array}$ & $\begin{array}{c}\text { Beam } \\
\text { Current } \\
\text { (ma) }\end{array}$ \\
\hline 1 & 50 & 4 & 14 & 75 & 16 \\
2 & 50 & 4 & 15 & 100 & 4 \\
3 & 50 & 8 & 16 & 100 & 8 \\
4 & 50 & 8 & 17 & 100 & 12 \\
5 & 50 & 8 & 18 & 100 & 4 \\
6 & 50 & 12 & 19 & 100 & 12 \\
7 & 50 & 12 & 20 & 100 & 16 \\
8 & 16 & 21 & 125 & 12 \\
9 & 50 & 4 & 22 & 125 & 16 \\
10 & 75 & 4 & 23 & 125 & 4 \\
11 & 75 & 8 & 24 & 150 & 12 \\
12 & 75 & 12 & 25 & 150 & \\
13 & 75 & 12 & & & \\
\hline
\end{tabular}

\section{DATA ANALYSIS}

Results from two typical tests are reported in Figure 3. The general pressure/focus interaction demonstrated in Figure 3 was observed in all of the tests conducted.

A meaningful correlation of the test data requires that all data be normalized and presented in some standard form. To provide the necessary correlation, the absolute variation in sharp focus, in digits, was converted to a percent change in sharp focus, using the value of sharp focus at a chamber pressure of $1 \times 10^{-4}$ torr as the basis for computing the percentage variation. Figure 4 presents the data of Figure 3 in the normalized furm.

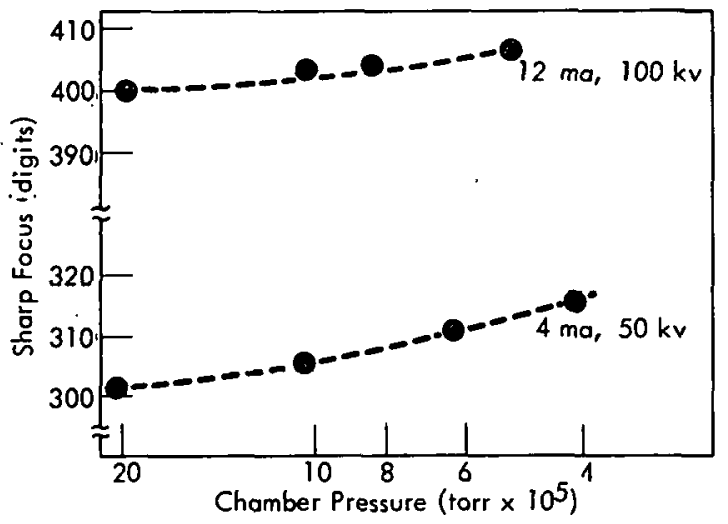

Figure 3. TYPICAL VARIATION IN SHARP FOCUS WITH PRESSURE.

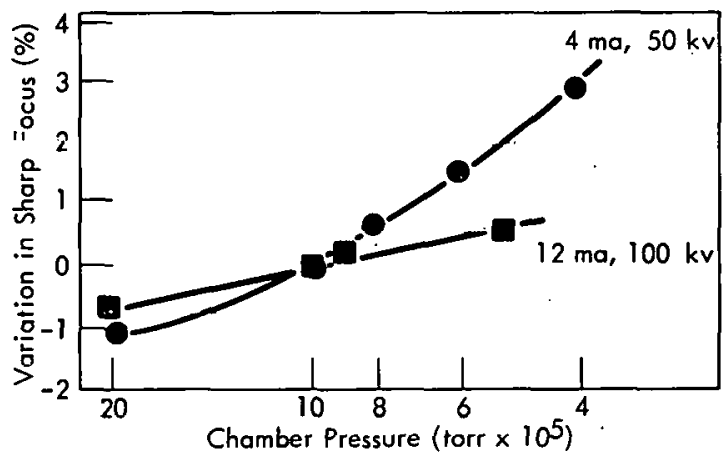

Figure 4. TYPICAL PERCENTAGE VARIATION IN SHARP FOCUS WITH PRESSURE. 
A straight-line, least-squares fit was applied to each of the 25 sets of experimental data. The fit took the form:

$$
\frac{f_{o}-f}{f_{o}}=A \log \frac{p}{10^{-5}}+B
$$

where:

$f_{0} \quad$ represents the focus control setting for a sharp focus at a chamber pressure of $1 \times 10^{-4}$ torr,

$f$ the focus control setting for a sharp focus at any chamber pressure, $p$, and

$p$

the chamber pressure, torr $\left(10^{-4} \geqslant \rho \geqslant 10^{-5}\right)$.

$A$ and $B$ are constants for any given combination of beam current, accelerating voltage, and welding geometry $(B \approx-A)$.

The term $p / 10^{-5}$ is the chamber pressure (in units of $10^{-5}$ torr) and the term $f_{o}-f / f_{o}$ is the corresponding fractional change in sharp focus from the original focus value at $1 \times 10^{-4}$ torr.

The slope of the curve, A, is proportional to the "pressure sensitivity" of the particular beam current-accelerating voltage combination being evaluated and provides an adequate measure of the pressure/focus interdependence.

A value of $A$ was calculated for each of the 25 sets of experimental data. Only data obtained at chamber pressures between $1 \times 10^{-4}$ and $1 \times 10^{-5}$ torr were considered. By restricting the calculations to pressures in this range, a reasonably accurate, straight-line fit could be accomplished; and, since vacuum EB welding is typically performed at chamber pressures between $1 \times 10^{-4}$ and $1 \times 10^{-5}$ torr, this restriction is justified.

Figure 5 demonstrates the variation that occurs in the calculated value of $A$ as a function of increasing accelerating voltage for a 4 -ma electron beam. The curve shows the typical peaking and decrease in the magnitude of the pressure sensitivity as the accelerating voltage increases. This particular plot indicates a maximum sensitivity occurring near an accelerating voltage of $75 \mathrm{kv}$, with the sensitivity decreasing as the accelerating voltage is increased beyond the 75-kv value.

A similar observed variation in the sensitivity of the pressure/focus interaction as a function of electron beam current is indicated in Figure 6 for an accelerating voltage of $100 \mathrm{kv}$.

The calculated values of $A$ are summarized for all of the experimental data as a function of the accelerating voltage in Figure 7. Each data point denotes the average value of $A$ for all of the beam currents evaluated at each accelerating voltage $(50,75,100,125$, and $150 \mathrm{kv})$ used during this study. The bars indicate the spread due to the different beam currents, with values of $A$ above the average being associated with the lower beam currents. 


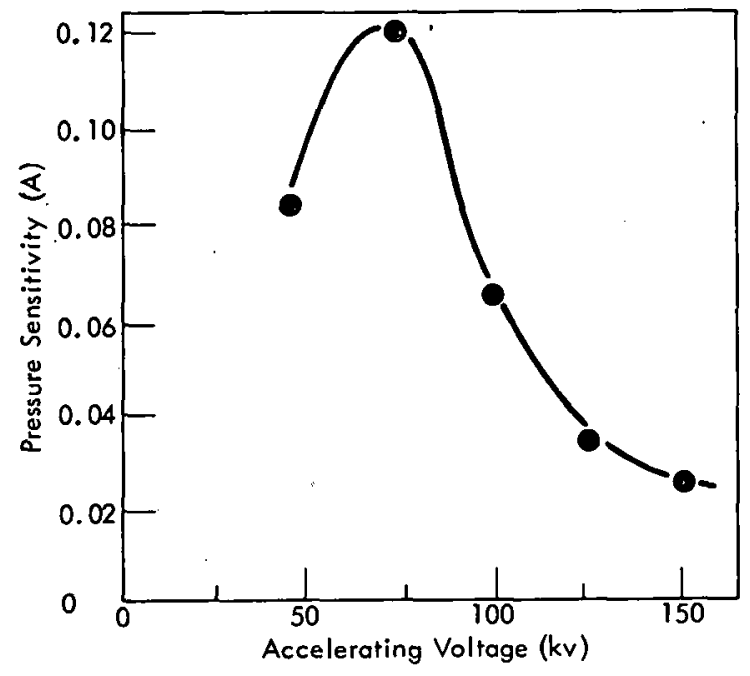

Figure 5. VARIATION IN PRESSURE SENSITIVITY, A, WITH ACCELERATING VOLTAGE. (Beam Current $=4$ ma)

beam current $(4,8,12$, and $16 \mathrm{ma})$ included in the tests. The bars indicate the spread due to the variation in the accelerating voltage.

The data presented in Figures 7 and 8 provide the means, when used with Equation 1, to predict, for any combination of beam current and accelerating voltage, the variation in electron beam sharp focus that would occur for any given change in chamber pressure. The data presented in Figures 7 and 8 are, however, valid only for the welding machine used for this test program and only if the electron beam is focused at the same distance $(23 \mathrm{~cm})$ below the heat shield.

\section{PRESSURE/FOCUS INTERACTION PROCESS}

The pressure dependence of the electron-beam sharp focus suggests a basic causative factor related to "collision" processes between the electrons in the beam and the residual nitrogen and oxygen molecules that comprise the reduced atmosphere in the welding chamber. Two collision processes are possible: A primary beam electron may interact with a nitrogen or oxygen molecule, with the final result being the scattering and loss of the beam electron. Removal of the electron from the beam will, in theory, reduce the magnitude of the electromagnetic field that must be generated in the focus coil to control the focusing of the beam. To evaluate the effect of electron loss from the beam on the current in the focus coil required to maintain beam sharp focus at a given distance from the heat shield, a test was conducted to relate variations in for.us roil current for sharp focus with reduction in beam current.

A 10-ma, 60-kv beam was focused on a tungsten target. Optical focusing was used. The beam current was then reduced in one-ma steps, with the corresponding sharp focus being determined for each value of the beam current. The results of this test, seen in Figure 9 , demonstrate the correlation between the variation in beam current and the change in the electron-beam focus. Results of this test eliminate simple scattering as a significant factor in explaining the pressure/focus interdependence. 


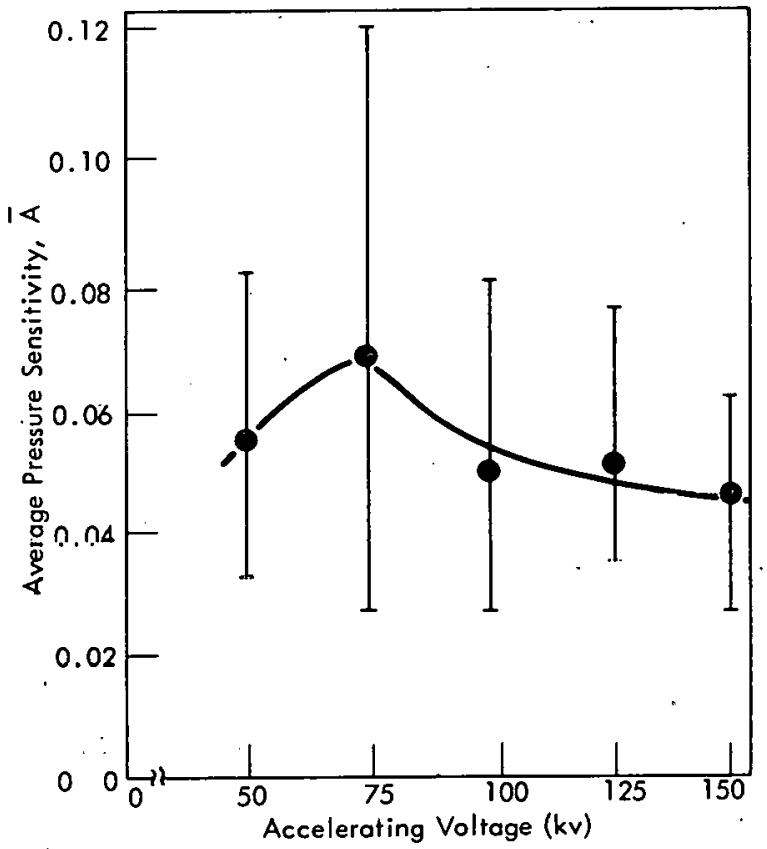

Figure 7. AVERAGE PRESSURE SENSITIVITY VARIATION WITH ACCELERATING VOLTAGE.

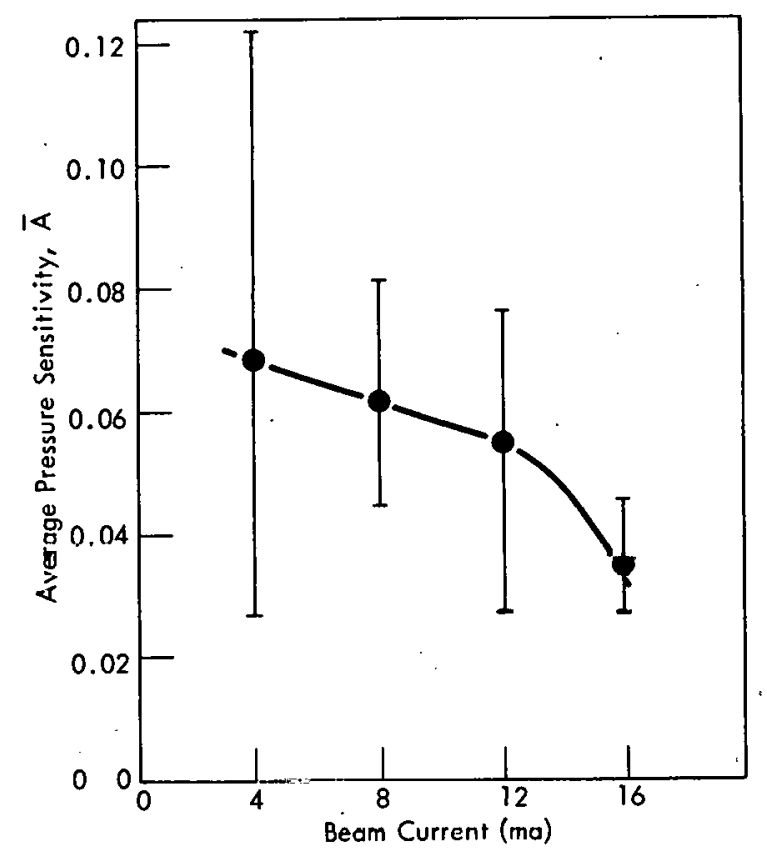

Figure 8. AVERAGE PRESSURE SENSITIVITY VARIA. TION WITH BEAM CURRENT.

The observed pressure/focus interdependence is due primarily to a second type of collision process, an electron/nitrogen molecule or electron/oxygen molecule interaction known as space-charge neutralization. (5) Figure 10 points out the dynamic forces acting on a focused electron beam with no space-charge neutralization. At conditions of equilibrium, the focusing, or beam compression, force, $f_{f}$, produced by the electromagnetic field in the focus coil is of the proper magnitude to counteract the mutual-repulsion force, $f_{r}$, produced by the negative charge carried by each electron in the beam, with the resultant beam focus occurring at some distance, $d$, below the heat shield.

Space-charge neutralization results from the ionization of residual nitrogen or oxygen - molecules by interaction with the high-energy electrons in the beam. The positive-charge ions are, because of the potential distribution in the beam, attracted to, and trapped, in the

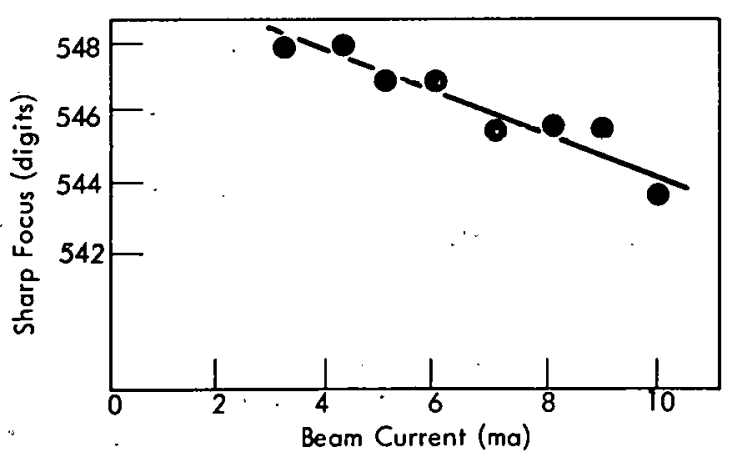

Figure 9. SHARP FOCUS VARIATION WITH BEAM CURRENT. (Accelerating Voltage $=60 \mathrm{kv}$ )

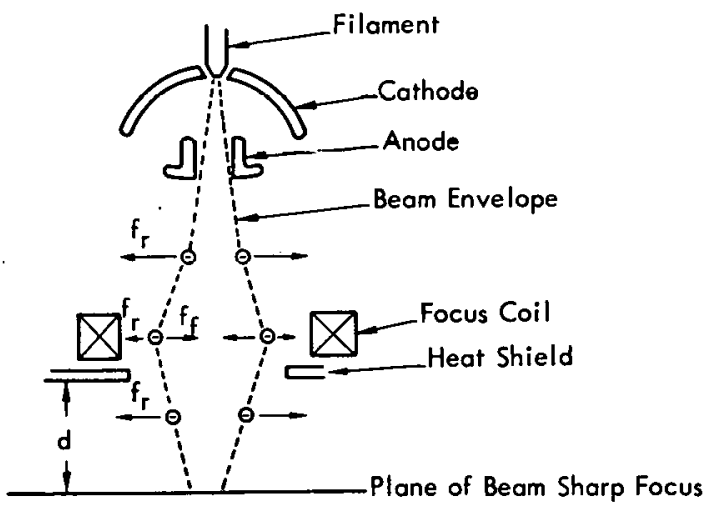

Figure 10. FORCES ACTING ON A FOCUSED ELECTRON BEAM. 
center of the beam. The accumulation of these trapped positive ions in the center of the beam partially neutralizes the mutual-repulsion force, $f_{r}$, generated by, and acting on, the individual electrons.

Under steady-state conditions, the electron repulsion forces and the beam compression forces (caused by the action of the focusing coil and positive ion trapping) combine to provide a net force that results in the beam sharp focus occurring at some distance, $d$. If the chamber pressure is then increased, the number of nitrogen and oxygen molecules available for ionization and trapping increase accordingly. As a result, neutralization of the repulsion forces, $f_{r}$, is increased, causing an increase in the net focusing force and reducing the value of $d$. To maintain the beam sharp focus at the original distance from the heat shield, the current through the focus coil must decrease to compensate for the added focusing effect due to space-charge neutralization. Conversely, focus coil current must be increased as chamber pressure decreases to maintain beam sharp focus at a given location, due to the reduction in space-charge neutralization at the lower pressures. At some chamber pressure, $p_{0}$, the number of positive ions generated is sufficient to completely neutralize the repulsion forces acting on the electrons. At this pressure, trapping of the positive ions stops and additional pressure increases have no effect on the focusing of the beam. The pressure, $p_{0}$, at which complete space-charge neutralization is attained is given by:

$$
p_{o}=\frac{R}{\pi^{1 / 2} r^{2} \mathrm{P}}\left[\frac{\mathrm{m}}{\mathrm{M}} \times \frac{\mathrm{V}_{\mathrm{T}}}{\mathrm{V}}\right]^{1 / 2},
$$

where:
$R$ represents the radius of the beam in the plane of the focus coil $(\mathrm{cm})$,
$r$ the radius of the beam in the plane of sharp focus $(\mathrm{cm})$,
P the specific ionization of the beam electrons (ions $/ \mathrm{cm} /$ torr),
$\mathrm{m}$ the mass of the electron (g),
M the mass of the positive ion (g)
$V_{T}$ the equivalent gas temperature of the positive ion (volts), and
$\checkmark$ the energy of the beam electrons (volts).

Substituting typical values for the present tests into Equation 2:

$$
\begin{aligned}
& R=4.0 \times 10^{-1} \mathrm{~cm} \\
& r \quad=2.5 \times 10^{-2} \mathrm{~cm} \\
& m=9.1 \times 10^{-28} \mathrm{~g} \\
& M=4.7 \times 10^{-23} \mathrm{~g}\left(\text { for } \mathrm{N}_{2}\right)
\end{aligned}
$$




$$
\begin{aligned}
& V_{T}=2.6 \times 10^{-2} \text { volts }(\text { at } 30 \mathrm{~K}) \\
& P \quad=2.6 \times 10^{-1} \text { ions } / \mathrm{cm} / \text { torr when } \mathrm{V}=50 \mathrm{kv} \\
& \mathrm{P} \quad=2.0 \times 10^{-1} \text { ions } / \mathrm{cm} / \text { torr when } \mathrm{V}=100 \mathrm{kv}
\end{aligned}
$$

gives the results:

$$
\begin{gathered}
p_{o}=4.4 \times 10^{-3} \text { torr, when } V=50 \mathrm{kv} \text {, and } \\
p_{o}=4.0 \times 10^{-3} \text { torr, when } V=100 \mathrm{kv}
\end{gathered}
$$

A comparison of the calculated values of $p_{o}$ for accelerating voltages of 50 and $100 \mathrm{kv}$ with the data presented in Figure 3 shows the trend of the curves, if extrapolated, to reach minimum values of sharp focus in the general region predicted by Equation 2.

The specific ionization, $P$, in Equation 2 is inversely proportional to the accelerating voltage, $\checkmark$. This inverse relation explains, in Figure 7, the decrease in the magnitude of the pressure/focus effect as the accelerating voltage increases. At higher voltages, the rate of positive ion formation, for a given beam current, decreases, reducing the effect of the space-charge neutralization.

\section{WELD EVALUATION}

The significance of the pressure/focus interaction is of importance to production applications only if the quality of a weld can be appreciably affected by the changes in chamber pressure that are typically encountered during vacuum electron beam welding.

To assess the importance of the focus changes due to pressure variations in the welding chamber, three series of bead-on-plate welds were made on a single plate of Type 6061-T6 aluminum alloy. Each series of welds were made at a fixed beam current, accelerating voltage, geometry, and welding speed. Electron-beam sharp focus was determined optically at the surface of the aluminum plate at a chamber pressure of $4.5 \times 10^{5}$ turr. A weld was then made at each of several different chamber pressures between $4 \times 10^{-5}$ and $1.5 \times 10^{-4}$ torr. All welding parameters, including focus, remained fixed during each series of welds. Only the chamber pressure was varied between the individual welds. Finally, the welds were sectioned and penetration and surface width were measured.

The results are reported in Figure 11. Each data point is the average of four measurements. The bars indicate the variation among the several penetration measurements averaged to provide each data point shown in the graph.

The variation in penetration as a function of pressure was most pronounced for the data shown in Graph a, with a maximum measured variation of $18 \%$. Graph b shows a maximum variation of $12 \%$ and Graph $c$ indicates a change of approximately $5 \%$.

Surface weld width variations were not significant in Graphs b and c. Measured variation for the lowest-energy weld (Graph a) was, however, of importance, having a value of $22 \%$. 


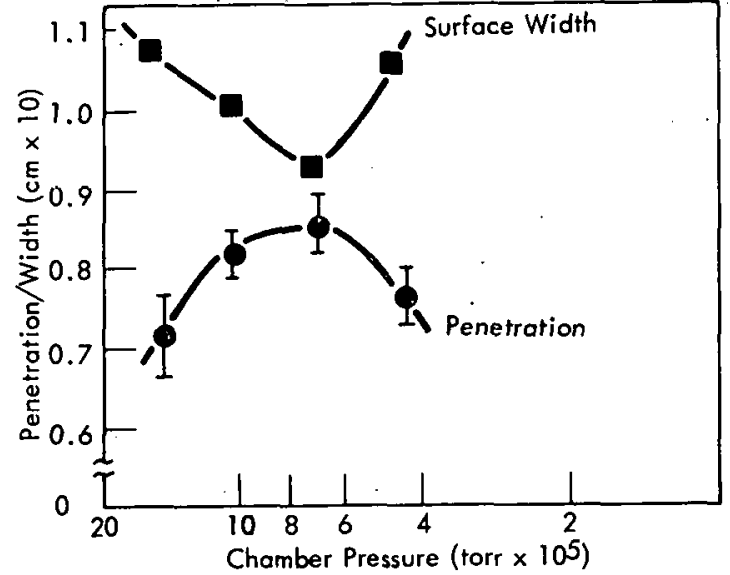

(a) At $4 \mathrm{ma}, 75 \mathrm{kv}, 25 \mathrm{~cm} / \mathrm{min}$.

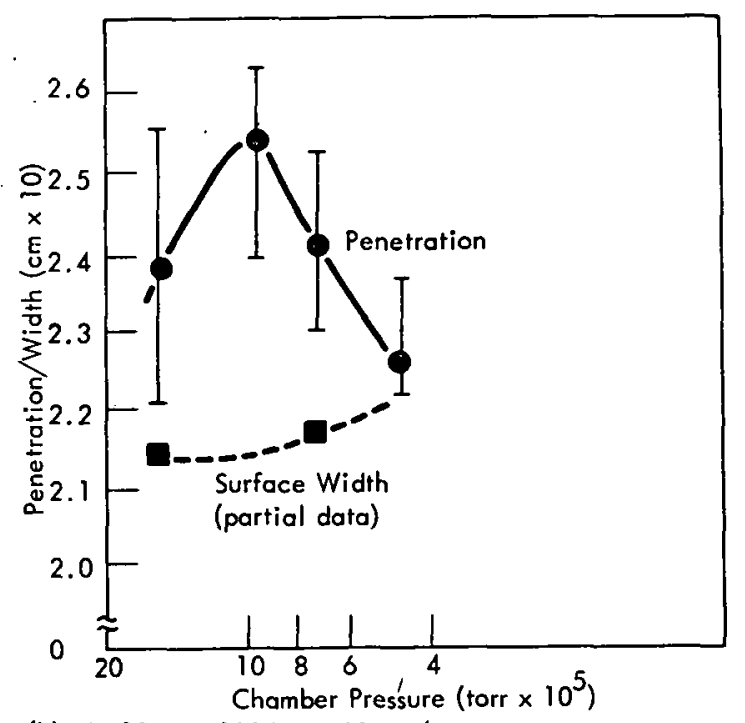

(b) At $10 \mathrm{ma}, 100 \mathrm{kv}, 200 \mathrm{~cm} / \mathrm{min}$.

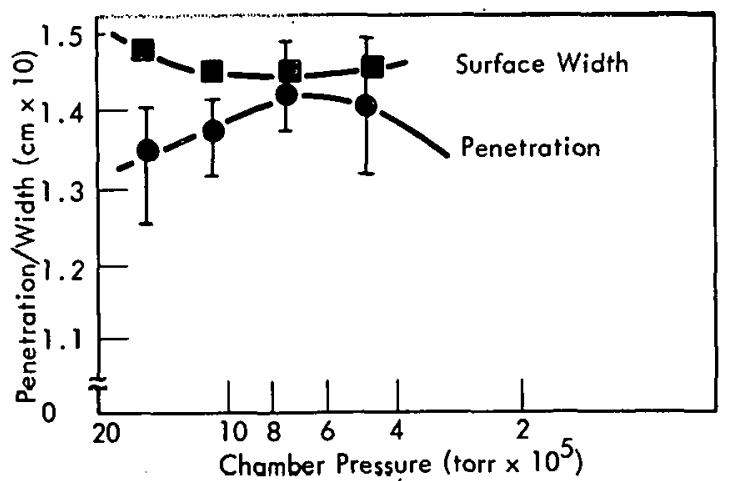

(c) At $8.4 \mathrm{ma}, 50 \mathrm{kv}, 25 \mathrm{~cm} / \mathrm{min}$.

Figure 11. VARIATION IN WELD PENETRATION AND WIDTH WITH PRESSURE. (At Different Beam Currents, Accelerating Voltages, and Welding Speeds: Type 6061-T6 Aluminum )
It is apparent that, in eacti series, the maximum penetration did not occur near the initial pressure $\left(4.5 \times 10^{-5}\right.$ torr $)$ where beam sharp focus was optically determined, but rather at a higher chamber pressure. Since maximum penetration is usually obtained with the electron beam focused slightly below the surface, this fact would indicate that the initial sharp focus was in error and that the beam was not focused at the surface, but instead rather deeply into the material. Then, as the chamber pressure increased, the beam sharp focus point moved nearer to the surface (due to the increased space-charge neutralization effect) and the penetration increased accordingly.

To assess the effect that temperature changes (preheating) might have had on the results shown in Figure 11, the test series of Graph a was repeated. As in the original test, beam current, accelerating voltage, and welding speed remained constant during the test. Sharp focus at the surface of the plate was, however, determined optically at each pressure prior to making a weld. The results of this test are indicated in Figure 12. The penetration data from Figure 11, Graph a, are replotted for comparison purposes.

Figure 12 demonstrates the increase in penetration that would be expected as a result of the preheating effect and verifies that preheating effects cannot account for the changes in penetration shown in Figure 11.

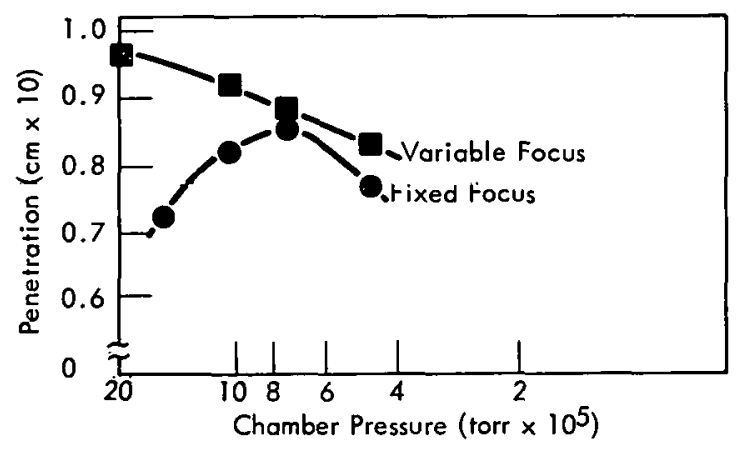

Figure 12. VARIATION IN PENETRATION WITH PRESSURE. (At $4 \mathrm{ma}, 75 \mathrm{kv}$, and $25 \mathrm{~cm} / \mathrm{min}$ ) 
Data similar to those shown in Figure 11 are presented in Figure 13 for similar tests conducted using Type 304L stainless steel. To completely. eliminate any effects due to preheating, each individual bead-on-plate weld included in Figure 13 was made on a separate coupon of Type 304L stainless steel.

Each data point plotted in Figure 13 represents the average of several independent penetration measurements. The bars denote the spread in the individual measurements at each of the pressures investigated. The maximum variation in penetration $(8.4 \%)$ occurs in Graph c. Corresponding values for Graphs a and b are 3.4 and $4.3 \%$, respectively.

\section{CONCLUSIONS}

The following conclusions can be stated as the result of this study:

1. Focusing of an electron beam can be significantly influenced by variations in pressures normally encountered in the welding chamber during electron-beam welding.

2. The character of the pressure/focus interaction is such that an increase in pressure enhances the beam "compression" effect of the focusing coil, causing the point of minimum beam diameter, or sharp focus, to move nearer to the focus coil.

3. Variations in beam focus resulting from typical changes in the welding chamber pressure are sufficient to affect the qualities, particularly penetration, of the weld being made. Low-energy, partial-penetration welds in low-density metals, such as aluminum, are the most susceptible. Average penetration variations in excess of $20 \%$ may occur.

4. An analytical prediction of the magnitude of the pressure/focus interaction for all combinations of welding parameters is sufficiently complex to be impractical. A realistic

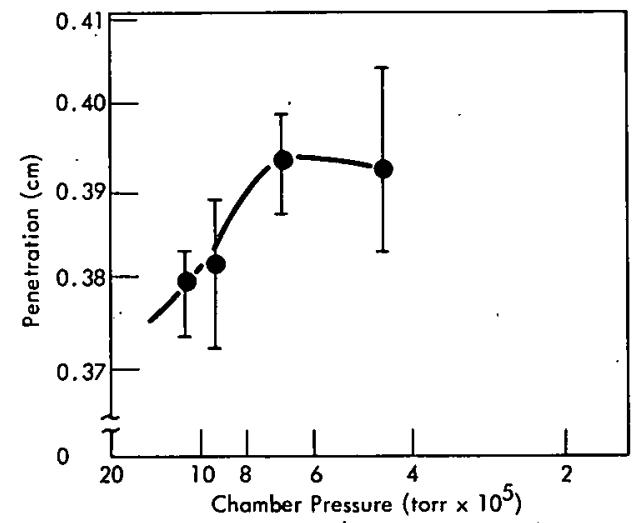

(a) At $7 \mathrm{mo}, 100 \mathrm{kv}, 50 \mathrm{~cm} / \mathrm{min}$.

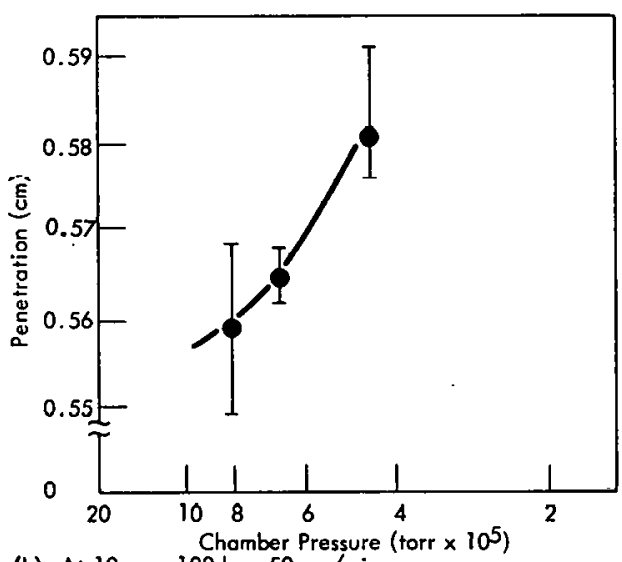

(b) At $10 \mathrm{ma}, 100 \mathrm{kv}, 50 \mathrm{~cm} / \mathrm{min}$.

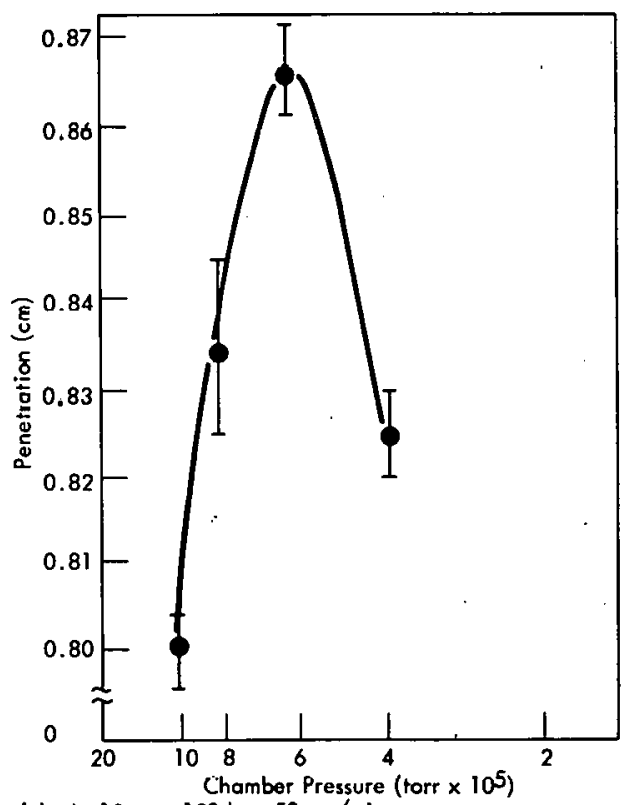

(c) At $12 \mathrm{mo}, 120 \mathrm{kv}, 50 \mathrm{~cm} / \mathrm{min}$.

Figure 13. VARIATION IN WELD PENETRATION WITH PRESSURE. (At Different Beam Currents, Accelerating Voltages, and Welding Speeds; Type 304L Stainless Steel) 
prediction of the magnitude of the effect can best be determined experimentally for a particular set of welding parameters.

5. Welding precision and repeatability require that consideration be given to the potential effects of chamber pressure fluctuations, especially for low-energy welds. Welds having unusually severe requirements for accuracy and repeatability may necessitate the consideration of chamber pressure control. 


\section{REFERENCES}

(1) Weidner, C. W. and Schuler, L. E.; "Effect of Process Variables on Partial Penetration Electron Beam Welding", Welding Journal, 52, pp 114-s - 119-s (1973).

(2) Sandstrom, D. J., Buchen, J. F., and Hanks, G. S.; "On the - Measurement and Interpretation and Application of Parameters Important to Electron Beam Welding", Welding Journal, 49, pp 293-s - 300-s (1970).

(3) Konkol, P. J., Smith, P. M., Willebrand, C. F., and Conner, L. P.; "Parameter Study of Electron Beam Welding", Welding Journal, 50, pp 765-776 (1971).

(4) Huber, R. A. and Turner, P. W.; "Electron Beam Welding at the Oak Ridge Y-12 Plant", Welding Journal, 48, pp 787 - 799 (1969):

(5) Linder, E. G. and Hernquist, K. G.; "Space-Charge Effects in Electron Beams and Their Reduction by Positive Ion Trapping", Journal of Applied Physics, 21, pp 1088-1097 (1950).

(6) Friedlander, G. and Kennedy, J. W.; Nuclear and Radiochemistry; Chap 7, p 196; John Wiley and Sons, Inc, New York, New York (1955). 
DISTRIBUTION

Atomic Energy Commission - ORO

Hickman, H. D.

Zachry, D. S., Jr

Oak Ridge Gaseous Diffusion Plant

Wilcox, W. J., Jr

Winkel, R. A.

Oak Ridge Y-12 Plant

Alvey, H. E.

Brandon, G. W., Jr (5)

Burditt, R. B.

Burkhart, L. E.

Butturini, W. G.

Denny, A.

Foulk, D. L.

Fraser, R. J.

Gritzner, V. B.

Hensley, C. E.

Jones, F. W.

Kahl, K. G.

Keith, Alvin

Kite, H. T.

Lundin, M. I.

Oliphant, G. W.

Perry, A. E.

Phillips, L. R.

Smith, H. F., Jr

Smith, R. D.

Stoner, H. H.

Tilson, F. V.

Weathersby, W. E.

Whitson, W. K.

Yaggi, W. J.

Y-12 Central Files (5)

Y-12 Central Files (master copy)

$Y-12$ Central Files (route)

$Y-12$ Central Files $(Y-12 R C)$

Paducah Gaseous Diffusion Plant

Millican, $R$.

In addition this report is distributed in accordance with the category, UC-38, Engineering and Equipment, as given in the USAEC Standard Distribution Lists for Unclassified Scientific and Technical Reports, TID-4500. 